DOI: $\underline{\text { https://doi.org/10.24297/jssr.v15i.8750 }}$

\title{
Post-Traumatic Stress Disorder (PTSD) Effect of Coronavirus (COVID-19) Pandemic and Role of Emotional Intelligence
}

\author{
Aida Mehrad \\ Universitat Autònoma de Barcelona (UAB), Spain Department of Basic, Developmental and Educational \\ Psychology
}

https://orcid.org/0000-0003-4364-5709

mehrad.aida@gmail.com

\begin{abstract}
Uncommon events during different decades and centuries create several challenges in the human lifestyle. Truthfully, individuals with any circumstances that have been occurred throughout their life illustrate various reactions and behaviours. In some cases, they report some issues such as Post-Traumatic Stress Disorder (PTSD) that is related to mental health which affected by any type of natural disasters, sickness, close relative dead, war, etc. At present, one of the crucial pandemic disasters caused by worldwide disease and death rates amongst individuals is Coronavirus (Covid-19) that has been spread enormous worries and anxiety in every society and country. The majority of individuals experienced this disaster and some of them demonstrate dissimilar types of anxiety and PTSD. The current literature review attempts to clarify the relation between Coronavirus (COVID-19) and PTSD based on the most recent investigations and reports, then link them to the role of Emotional Intelligence in reducing diverse unusual stress and severe nervousness such as PTSD that is the consequence of Coronavirus (COVID-19).
\end{abstract}

Keywords: Post-Traumatic Stress Disorder (Ptsd), Coronavirus (Covid-19), Emotional Intelligence

\section{Introduction}

\subsection{Post-Traumatic Stress Disorder (PTSD) Symptoms and Causes}

PTSD assumed as psychological unbalance that following experience traumatic events; individuals with this disorder frequently re-experience traumatic events, expose avoidance behaviour, and become irritable. Accurately, PTSD is a severe anxiety disorder that can consequence in serious disability across a number of domains of functioning. PTSD symptoms have similarly been associated with poor quality of life (Tang, Pan, Yuan, \& Zha, 2017). Based on most research PTSD may be the continuance of an acute stress disorder and it may take place 6 months after the event happened. For the most part, the majority of individuals overcome the shock that an obvious event can reason without the necessity for additional support. In some cases, the victim's suffering can be protracted for more than a month after exposure to trauma and meaningfully interfere with the individual's working or social life; in this case, the diagnosis of PTSD must be made. This disorder develops as a consequence of one or more physical or psychological traumatic events, exposure to natural disasters such as losing close relative, earthquakes, fires, floods, storms, tidal wave; war and conflict, torture, car accidents, theft, plane crashes, diseases with poor prognosis, complicated or traumatic mourning, maltreatment and physical and sexual abuse in infantile, victimization and discrimination based on gender, sexual orientation, and gender identity (Roccella, 2020). In a similar study, Pugach, Campbell, and Wiscois (2020) reported PTSD is a psychiatric disorder that may rise up subsequent a trauma exposure, defined as the feeling, witnessing, or learning of actual or threatened death, serious injury, or sexual violence. 
According to these mentioned causes, Individuals express different symptoms. These symptoms comprised flashbacks, hallucinations, and nightmares (sleeping problems), repetitive and distressing images or sensations, uncommon physical feelings such as pain, sweating, feeling sick or trembling, difficulty concentrating; additionally, some individuals have continuous negative feelings about their experience, regularly asking themselves questions that stop them coming to terms with the event. We have to add one main point, individuals based on their background and culture show different reactions; likewise, we cannot refer the parallel symptoms to all of them. Usually, these symptoms progress during the first month after a traumatic event. But in a minority of cases, there may be a delay of months or even years before symptoms start to appear ("Posttraumatic stress: How can you help a loved one?", 2019).

However, after explanations about PTSD (definitions, causes, and symptoms), the current literature review focuses on Coronavirus (Covid-19) as one of the main reasons in appearing of PTSD among individuals, profoundly; and in following examine the role of emotional intelligence to reducing of PTSD.

\subsection{Coronavirus and Mental Health: PTSD}

Coronavirus (Covid-19) as an uncontrolled and worldwide virus happened at the Huanan seafood market in Wuhan, the capital of China's Hubei province, and based on the reports the first case suffering from Covid-19 was in that city. The virus was first recognized in December 2019 and has subsequently spread universally, resulting in the current 2019-20 coronavirus pandemic ("WHO Timeline - COVID-19", 2020). Based on scientists' reports the coronavirus originated from bats but first passed through an intermediary animal in the same way that another coronavirus - the 2002 Sars outbreak - moved from horseshoe bats to cat-like civets before infecting humans. One animal that implicated as an intermediary host between bats and humans is the pangolin, and all of these three are in mammals' taxonomy ("Eating pangolins to extinction", 2014; "How did coronavirus start and where did it come from? Was it really Wuhan's animal market?", 2020).

Coronavirus (Covid-19) shows different types of symptoms, and the common symptoms comprise fever, cough, fatigue, shortness of breath, and loss of smell and taste in both gender amongst children, teenagers, youths, and elder people. Coronavirus is impacting global health and mental health and creates several mentality issues such as PTSD which being the most frequently encountered followed by behavioural and psychological disorders (Torales, Higgins, Castaldelli-Maia \& Ventriglio, 2020). For that reason, the existing pandemic poses an unlimited risk for psychological and psychiatric disease. In actual fact, this disease caused by an up till now (May 2020) unrecognized infection with no vaccines or approved drug regimens in place further adds to the distress. World Health Organization (WHO) in recent times transformed the term 'social distancing' to 'physical distancing' to make individuals feel less lonely and isolated. A previously meta-analysis had concluded that loneliness is a risk factor for all-cause mortality or death. Individuals living away from their families for education or work, or otherwise separated from their loved ones are at a higher risk for developing mental health problems such as depression, anxiety, etc. Elderly people living by yourself are likewise significantly predisposed (Sood, 2020; Shah, Kamrai, Mekala, Mann, Desai, \& Patel, 2020).

\subsection{Emotional Intelligence and Its Role in PTSD?}

According to different natural disasters and difficulties such as Coronavirus (Covid-19) that may happen during individuals' life and appear various mental health same as PTSD. This section focuses on individuals' emotional intelligence to recognizing how it can reduce PTSD in an uncommon situation.

Emotions as inner feeling commonly considered by different groups of psychologists and sociologists, because they believe that emotions most of the time are effective and change approach, reactions, and feelings of individuals based on their activities and normal lifestyle; In this case, we can say that PTSD is not excluded of this fact (Power \& Fyvie, 2013). Moreover, recognizing and knowing more about emotions and their role in individuals' social and personal life is an important fact; and its better start to be familiar with the scientific definition of emotion or in the other words, emotional intelligence. 
The emotional intelligence well-defined as the capacity to distinguish, evaluate, and revision the emotions of self and others in private and social life for determining individuals' performance (Harms \& Credé, 2010). As it happens, emotional intelligence consists of 4 main factors: 1) perception of emotion, 2) managing own emotions, 3) managing others' emotions, and 4) utilization of emotion, that explains how individuals show their emotions in private and social life (Schutte \& Malouff, 2011). Emotional intelligence is an effective factor that plays a great role in individuals' feelings and approaches; also, it is a way of being smart which involves recognizing real feelings and applying it to make an accurate decision on the duration of life. Accurately, this factor controls moods and aims in diverse situations and manages them in communication among individuals (Darabi, 2012). Additionally, it predicts two facets of personal and social individuals' life (Lopes, Brackett, Nezlek, Schütz, Sellin, \& Salovey, 2004). Emotional intelligence factors likewise focus on two facets of the inner and outward of individuals and have a unique impact on individuals feeling (Kernbach \& Schutte, 2005). In a similar investigation, Akintayo and Babalola (2012) reported that emotional intelligence has a direct association with behaviours. As far as the association between emotional intelligence and feeling, the researchers clarified that emotional intelligence has a useful contribution to developing some abilities and feelings. This factor has a considerable proportion of individuals' positive opinions and behaviour. Kernbach and Schutte (2005) likewis e defined emotional intelligence as a potential to obtain abilities and adaptation for understanding, managing, and harness the emotions on two sides of self and others. Emotional intelligence is a kind of ability for knowing, assessing, and controlling individual reactions. In actual fact, this factor refers to skills to identify and check the emotions that appeared by a person in private and social situations. Also, Brackett, Rivers, Shiffman, Lerner, and Salovey (2006) defined emotional intelligence assumed as the ability to convey feelings and emotions among individuals that use this information for conducts their views and performances in private and social life. Schutte, Malouff, and Thorsteinsson (2013) described emotional intelligence is the capability to perceive others' emotions. Moreover, it expresses one's emotions that including social skills to build perception of emotion, utilization of emotion, managing own emotions, and managing others' emotions. In the following sentences, based on explanations of emotional intelligence focuses on definitions of its factors.

As stated above emotional intelligence comprised four factors, and perception of emotion determined as one of these factors. Truly, the perception of emotion refers to knowing the emotions associated with the facial and voice cues of others. Moreover, this factor described the awareness of one's body states toward emotions; likewise, it well-thought-out on any feelings that appear to others and impacts on their feelings, attitudes, and behaviours. In the main, perception of emotion as a great ability has a key role in accurate decision-making in dissimilar situations (Schutte et al., 2013).

Managing own emotions as another factor emphasis on self and attention to individual emotion. This factor involved confidence, flexibility, success orientation, creativity, change catalyst, and strength of mind (Darabi, 2012). Managing own emotions determined as an effective factor in self and contained within the core of emotional intelligence. This factor likewise well-defined as a regulator of emotions that conducts the targets of individuals in various ways and prepares sufficient conditions for improving relationships with others (Maul, 2012).

Managing others' emotions or social skills as a factor of emotional intelligence included regulating other emotions that are appropriate for their needs in various situations and goals (Schutte et al., 2013). This factor is definite as an influential controller that focuses on others toward their abilities and emotions in society and also considers their relationships that emerged by emotions in a different situation. The presence of managing others 'emotions leads to appropriate behaviour with others and do better responsibilities and affairs at the workplace (Darabi, 2012).

A study by Eshun, Eshun, and Yasenchak (2010) on the utilization of emotion as another emotional intelligence factor, reported this factor is harnessing the impacts of emotions in different states. Additionally, the utilization of emotion assumed as a solvable factor for complications that emerged in personal and social relationships. Correspondingly, this factor defined as a predictor for positive reactions such as personal efficacy and satisfaction (Platsidou, 2013). 


\subsection{Emotional Intelligence- The Mayer and Salovey Model}

The Mayer and Salovey Model assumed as a well-known model for emotional intelligence which was proposed by Mayer and Salovey (1997). This model is determined as a principle model for emotional intelligence that refers to the skills of the individuals in the process of emotional intelligence and social environment (Mayer\& Salovey, 1997; Brackett et al., 2006; Darabi, 2012). The Mayer and Salovey Model clarified the distinction between emotional intelligence factors and ability. It shows how each of the emotional intelligence factors matches or motivates the individual's ability and feeling. As mentioned above emotional intelligence has four main factors that focused on two sides, self-report and social relation. The individuals with these emotions and feelings show a high level of ability and performance in their personal and social life. They would be useful in predicting positive organizational behaviour. Based on the history of emotional intelligence, Charles Darwin (1872) was the first person that focused on emotions' value and evaluated these inner motivators in real life. In following, Thorndike (1920), Bar On (1988), and Goleman (1995) assessed emotional intelligence in various facets and definitions. On the other hand, the Mayer and Salovey Model (1997) focused on four factors of emotional intelligence and examined emotional abilities on two sides of self-report and social relation (Brackett et al., 2006; Darabi, 2012). According to the Mayer and Salovey Model, Alam (2009) explained that emotional intelligence assumed as the ability in perceiving and understanding emotional responses. The researcher explained that emotional intelligence affects basic human needs, activities, performances, feelings, and behaviours. Emotional intelligence has a close association with behavioural reactions and human abilities in society. In the study of Janke, Driessen, Behnia, Wingenfeld, and Roepke (2018) has been reported emotional intelligence has a contradictory relationship with PTSD; in truth, emotional intelligence has to be advance amongst patients with PTSD, then they show lowest symptoms. Therefore, patients need some inner practice related to their attitudes and beliefs. The patients have to distinguish themselves in two internal and external aspects (personal life and social life), then based on their achievement cope with their disorders and uncommon behaviour. In essence, the Mayer and Salovey Model focused on an individual's ability that as compared to others, prospected in two sides of an individual's life.

\section{Conclusion}

Emotional intelligence has to be considered as one of the imperative inner factors amongst those who are infected by PTSD regards Coronavirus (Covid-19) as a universal disaster. Emotional intelligence and its factors refer to the skills and capabilities of individuals and play as a positive motivator. In truth, emotional intelligence motivates individuals to care more about themselves and social life. Furthermore, with accurate recognition regards emotional intelligence, the low level of negative feelings and stress will reduce. It means that if individuals with PTSD recognize their feeling and attitude perfectly, they can cope with abnormal mental health. In actual fact, they have to know themselves (inner feeling) comprehensively; then there is this possibility to control mental disorders to recover and improvement with considering positive points in their life and following correct policies and protocol that offered from WHO, local government, and any other related organization. In truth, there is immense responsibility for the physical and mental health of individuals in every society that has been caring by all mentioned organizations. They have to support wisely individuals and prepare at least the basic facilities in an uncommon condition such as the current situation with Coronavirus (Covid-19) pandemic disaster that made numerous death rates and sickness; correspondingly, it effected more on the economic cycle with numerous unemployed that is threatening for every country.

Likewise, Coronavirus (Covid-19) leads to several infrequent mental health that needs more attention, care, and support by psychologists, psychiatrists, therapists, psychotherapists, counsellors, and social workers. Governments additionally have to provide educational programs on TV or online workshops to explain any main points that are necessary for knowing not only about avoiding Coronavirus (Covid-19), physical health, and hygiene; as well, about mental health and positive attitudes in isolation days. Truthfully, all the organizations and specialists have to explain clearly what will be happened for individuals' mental health after these types of blaster if they don't consider enough. 


\section{References}

1. Akintayo, D. I., \& Babalola, S. S. (2012). The impact of emotional intelligence on workers' behavior in industrial organizations. Journal of Human and Social Psychology, 4(2), 83-90.

2. Alam, M. M. (2009). The relationships between the emotional intelligence and job satisfaction: Empirical findings from higher education institution in Malaysia. Journal of Management and Social Science, 5(2), 124139.

3. Brackett, M. A., Rivers, S. E., Shiffman, S., Lerner, N., \& Salovey, P. (2006). Relating emotional abilities to social functioning: A comparison of self-report and performance measures of emotional intelligence. Journal of Personality and Social Psychology, 91(4), 780-795. doi:10.1037/0022-3514.91.4.780

4. Darabi, M. (2012). Emotional intelligence a literature review. Journal of Applied Science Research, 8(6), 29912997.

5. Eating pangolins to extinction. (2014, July 29). Retrieved from https://www.lucn.org/content/eatingpangolins-extinction

6. Eshun, J. P., Eshun, S., \& Yasenchak, R. (2010). Role of emotional intelligence and tacit knowledge in hypothetical management decisions: Support for a pedagogical shift in teaching business management students. The Educational Collaborative, 1-8.

7. Harms, P. D., \& Credé, M. (2010). Emotional intelligence and transformational and transactional leadership: A meta-analysis. Journal of Leadership \& Organizational Studies, 17, 5-17. https://doi.org/10.1177/1548051809350894

8. How did coronavirus start and where did it come from? Was it really Wuhan's animal market? . (2020, April 28). Retrieved from https://www.theguardian.com/world/2020/apr/28/how-did-the-coronavirus-startwhere-did-it-come-from-how-did-it-spread-humans-was-it-really-bats-pangolins-wuhan-animal-market

9. Janke, K., Driessen, M., Behnia, B., Wingenfeld, K., \& Roepke, S. (2018). Emotional intelligence in patients with posttraumatic stress disorder, borderline personality disorder and healthy controls. Psychiatry Res, 264, 290296. doi: 10.1016/j.psychres.2018.03.078.

10. Kernbach, S., \& Schutte, N. S. (2005). The impact of service provider emotional intelligence on customer satisfaction. Journal of Services Marketing, 19(7), 438-444. doi:10.1108/08876040510625945

11. Lopes, P. N., Brackett, M. A., Nezlek, J. B., Schütz, A., Sellin, I., \& Salovey, P. (2004). Emotional Intelligence and Social Interaction. Personality and Social Psychology Bulletin, 30(8), 1018-1034. https://doi.org/10.1177/0146167204264762

12. Maul, A. (2012). The validity of Mayer-Salovey-Caruso emotional intelligence test (MSCEIT) as measure of emotional intelligence. Emotion Review, 4, 1-9. https://doi.org/10.1177/1754073912445811

13. Mayer, J. D., \& Salovey, P. (1997). What is emotional intelligence? In P. Salovey \& D. Sluyter (Eds.), Emotional development and emotional intelligence: Educational implications (pp.3-31). New York: Basic Books.

14. Platsidou, M. (2013). Trait emotional intelligence predicts happiness, but how? An empirical study in adolescents and young adults. International Journal of Wellbeing, 3(2), 197-209. doi: 10.5502/ijw. v3i2.6 
15. Post-traumatic stress: How can you help a loved one? . (2019, August 7). Retrieved from https://www.mayoclinic.org/diseases-conditio ns/post-traumatic-stress-disorder/symptoms-causes/syc$\underline{20355967}$

16. Power, M. J., \& Fyvie, C. (2013). The role of emotion in PTSD: two preliminary studies. Behav Cogn Psychother, 41(2),162-72. doi: 10.1017/S1352465812000148.

17. Pugach, C. P., Campbell, A. A., \& Wiscois, B. E. (2020). Emotion regulation in posttraumatic stress disorder (PTSD): Rumination accounts for the association between emotion regulation difficulties and PTSD severity. J. Clin. Psychol, 76,508-525. https://doi.org/10.1002/jclp.22879

18. Roccella, M. (2020). Children and Coronavirus Infection (Covid-19): What to Tell Children to Avoid PostTraumatic Stress Disorder (PTSD). The Open Pediatric Medicine Journal, 10, 1-2. doi: $10.2174 / 1874309902010010001$

19. Schutte, N. S., \& Malouff, J. M. (2011). Emotional intelligence mediates the relationship between mindfulness and subjective well-being. Journal of Personality and Individual Differences, 50(7), 1116-1119. doi: 10.1016/j.paid.2011.01.037

20. Schutte, N. S., Malouff, J. M., \& Thorsteinsson, E. B. (2013). Increasing emotional intelligence through training: Current status and future directions. The International Journal of Emotional Education, 5(1), 56-72.

21. Shah, K., Kamrai, D., Mekala, H., Mann, B., Desai, K., \& Patel, R. (2020). Focus on Mental Health During the Coronavirus (COVID-19) Pandemic: Applying Learnings from the Past Outbreaks. Cureus ,12(3): e7405. doi:10.7759/cureus.7405

22. Sood, S. (2020). Psychological effects of the Coronavirus disease-2019 pandemic. Res Hum Med Educ ,7(1), 23-26.

23. Tang, L., Pan, L., Yuan, L., Zha, L. (2017). Prevalence and related factors of post-traumatic stress disorder among medical staff members exposed to H7N9 patients. International Journal of Nursing Sciences, 4(1), 6367. doi: 10.1016/j.ijnss.2016.12.002

24. Torales, J., O'Higgins, M., Castaldelli-Maia, J. M., \& Ventriglio, A. (2020). The outbreak of COVID-19 coronavirus and its impact on global mental health. International Journal of Social Psychiatry. https://doi.org/10.1177/0020764020915212

25. WHO Timeline - COVID-19. (2020, April 22). Retrieved from https://www.who.int/news-room/detail/27-042020-who-timeline---covid-19 